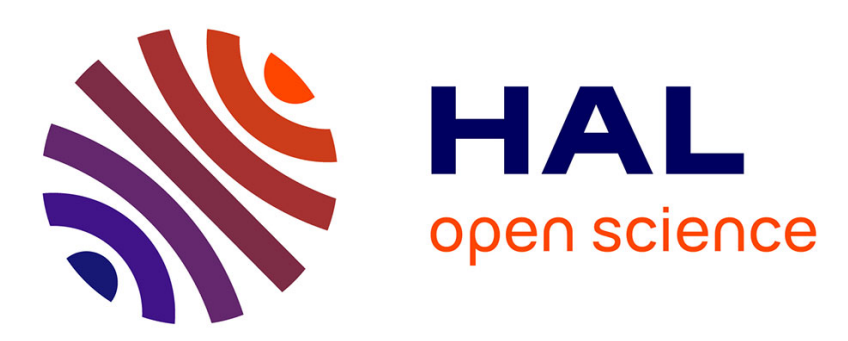

\title{
Parseval's Theorem Used for the Inductor Analysis in High-Frequency Boost Converters
}

\author{
A. Gutiérrez, Emmanuel Marcault, Corinne Alonso, Jean Paul Laur, David \\ Trémouilles
}

\section{- To cite this version:}

A. Gutiérrez, Emmanuel Marcault, Corinne Alonso, Jean Paul Laur, David Trémouilles. Parseval's Theorem Used for the Inductor Analysis in High-Frequency Boost Converters. ELECTRIMACS 2019 Selected Papers, pp.347-362, 2020, 978-3-030-56970-9. 10.1007/978-3-030-56970-9_26 . hal03100915

\section{HAL Id: hal-03100915 https://hal.laas.fr/hal-03100915}

Submitted on 6 Jan 2021

HAL is a multi-disciplinary open access archive for the deposit and dissemination of scientific research documents, whether they are published or not. The documents may come from teaching and research institutions in France or abroad, or from public or private research centers.
L'archive ouverte pluridisciplinaire HAL, est destinée au dépôt et à la diffusion de documents scientifiques de niveau recherche, publiés ou non, émanant des établissements d'enseignement et de recherche français ou étrangers, des laboratoires publics ou privés. 


\title{
Parseval's Theorem for the Inductor Analysis in High-Frequency Power Converters
}

\author{
A. Gutierrez ${ }^{1 *}$, E. Marcault ${ }^{1}$, C. Alonso ${ }^{2}$, J-P. Laur ${ }^{2}$, D. Tremouilles ${ }^{2}$ \\ ${ }^{1}$ CEA-Tech Occitanie, Toulouse - France. ${ }^{2}$ LAAS-CNRS, Toulouse - France
}

\begin{abstract}
Advances in GaN-HEMT devices have encouraged the development of power converters at megahertz-level. However, inductors for high-frequency power converters require innovative approaches to overcome challenging constraints in both power and frequency. In this context, this paper presents an extension of the Parseval's theorem for the inductor analysis based on the energy conservation principle in the time and the frequency domains. Our approach aims to provide insights about the inductor power losses using high-frequency parameters and the inductor current harmonics. The proposed approach disaggregates the power losses in the frequency-domain for the inductor power signals in the time-domain. Main findings from the presented methodology provide useful selection criteria for inductors in power converters given parameters of quality factor $(Q)$ and Self Resonance Frequency $(S R F)$. Simulation results show the impact of the inductor behavior on the switching losses. An experimental setup validates the proposed approach. A high-frequency boost converter is presented as a study case.
\end{abstract}

Keywords: Power Inductor, Quality Factor, Self Resonance Frequency, Boost Converter, GaN-HEMT.

\section{Introduction}

Traditional analysis of power converters requires design tools intended to deal with operation frequencies around hundreds of kilohertz [1]. However, 3 outstanding advances in Gallium Nitride - High Electron Mobility Transis4 tors (GaN-HEMTs) enlarge the operation condition of power converters to

\footnotetext{
*Corresponding author: alonso.gutierrezgaleano@cea.fr
} 
the range of megahertz [2][3]. Indeed, this extended bandwidth requires innovative design methodologies to achieve a trade-off between high-frequency and high-power conditions [4]. Additionally, these new generation of power converters should incorporate power inductors with both high current handling and high operation frequency [5][6].

As result, high-frequency parameters become more and more important for the analysis and selection of inductors during the design process of power converters [7][8]. Usually, applications of inductors in high-frequency take into account the manufacturer parameters of Self Resonance Frequency $(S R F)$ and quality factor $(Q)$. These $S R F$ and $Q$ parameters allow describing the inductor operation bandwidth and the associated power losses. However, these inductor parameters are few analyzed in the conventional design of power converters at kilohertz-level. Conversely, operation at megahertz-level should include the $S R F$ and $Q$ parameters in the design stage.

Additionally, the switching improvements provided by GaN-HEMTs can extend the operation frequency of power inductors to levels usually dedicated to radio-frequency applications. However, manufacturing constrains associated to ferromagnetic cores limit the scope of power inductors in highfrequency applications [9]. Therefore, manufacturing features and powerfrequency behavior require a suitable trade-off to improve the inductor performance in high-frequency power converters [10][11].

In this context, we proposed an innovative approach using the Parseval's theorem as a means to associate the power losses in the time-domain and the inductor behavior in the frequency-domain. The developed framework aims to be complementary to conventional and well known methodologies for the inductor selection and design of power converters. This approach provides insights about the impact of the quality factor $(Q)$ and the Self Resonance Frequency $(S R F)$ on the inductor current harmonics and the power losses. Simulation results suggest suitable criteria for a trade-off between the quality factor $(Q)$ and the power losses given feasible manufacturing features. Furthermore, this paper proposes an inductor model incorporating the $Q$ and $S R F$ parameters into a circuital model useful for the analysis of power converters.

This paper is organized as follows. Section 2 describes the power and fre- 

ponents.

quency behavior of power inductors considering high-frequency parameters. Section 3 presents the theoretical approach based on the Parseval's theorem to study the relation between power and frequency. Section 4 describes the proposed inductor model including SRF and Q parameters. Section 5 explains in detail the experimental setup to validate the proposed approach. Finally, an experimental high-frequency boost converter is implemented.

\section{Power inductor behavior in high-frequency}

This section describes the inductor behavior in a high-frequency power converter taking into account the quality factor $(Q)$ and the Self Resonance Frequency $(S R F)$. A high-frequency boost converter is presented as an illustrative example.

Fig. 1 shows the designed boost converter as a study case using a commercial reference of a power inductor. The switching frequency is set to $30 \mathrm{MHz}$ to take advantage of the switching characteristics of GaN-HEMTs. This boost converter increases the voltage from $200 \mathrm{~V}$ to $400 \mathrm{~V}$ with output power of $400 \mathrm{~W}$ and load of $400 \Omega$. In this design, the inductor is set to $8.2 \mu \mathrm{H}$ and the output capacitance is set to $220 \mathrm{pF}$. Furthermore, the studied converter focuses on the inductor performance considering ideal the other components to avoid their influence in the developed analysis.

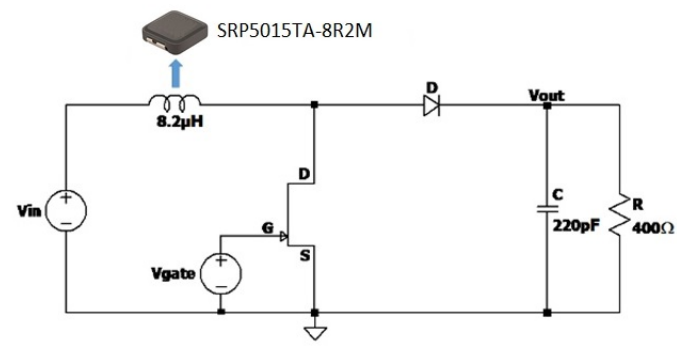

Figure 1: High-frequency boost converter with actual inductor and ideal associated com-

Fig. 2 depicts the frequency behavior of the associated inductor losses $R_{f}$ and the quality factor $Q_{f}$ for the power inductor of $8.2 \mu \mathrm{H}$ used in the designed boost converter. Additionally, Fig. 2 shows the $S R F$ of the studied power inductor. The inductive characteristics prevail in the region of 
frequencies lower than the $S F R$ and the capacitive characteristics prevail in frequencies higher than the $S R F . R_{f}$ and $Q_{f}$ of Fig. 2 are calculated using the inductor model provided by the manufacturer. The $R_{f}$ and $Q_{f}$ parameters depend on the actual inductor impedance $Z=|Z| \angle \theta$. The associated losses $R_{f}$ are defined as the real part of the inductor impedance by $R_{f}=|Z| \cos \theta$. The quality factor $Q_{f}$ expresses the relation between the stored and dissipated energy. The quality factor $Q_{f}$ in an inductor is given by $Q_{f}=X_{L} / R_{f}=\tan \theta_{L}$, where $X_{L}=|Z| \sin \theta$.

Frequency behavior of associated losses $\mathrm{R}_{\mathrm{f}}$

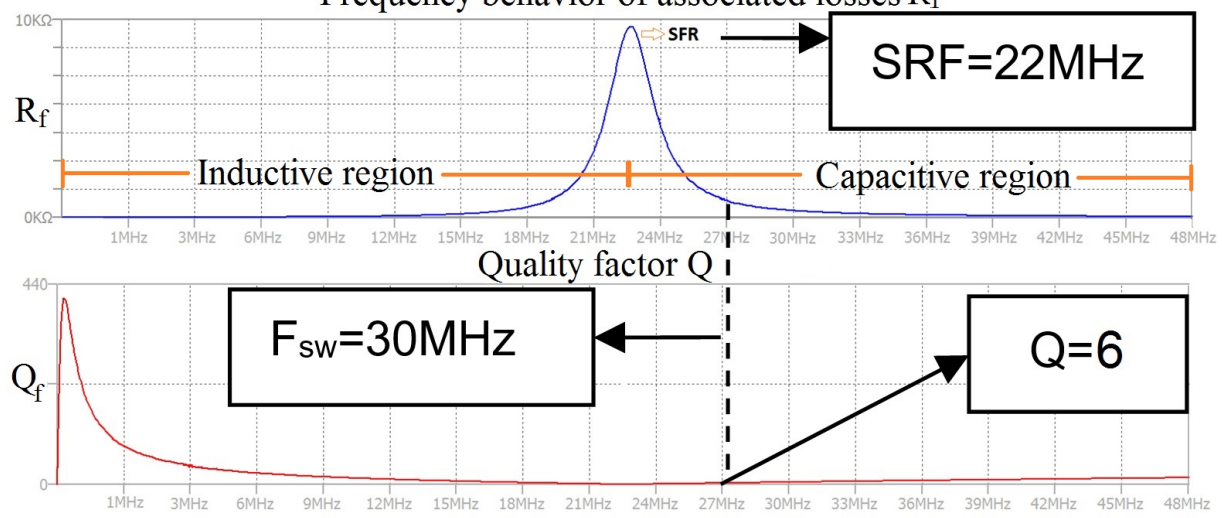

Figure 2: Frequency behavior of $R_{f}$ and $Q_{f}$ for the power inductor used in the designed boost converter.

The power inductor under study accomplish the requirements of inductance and current in the range of $\mathrm{KHz}$. However, it has a low performance in the range of $\mathrm{MHz}$ as shown in Fig. 2. The proposed analysis intentionally begins with this unsuitable inductor to assess and understand the influence of the high-frequency parameters in the inductor performance. This analysis is the first step to define selection criteria for high-frequency power inductors with a suitable trade-off between performance and feasibility.

Fig. 3 shows the simulation results comparing the inductor current in the case of an ideal inductor in series with a low resistance and the manufacturer model for the studied inductor. In addition, Fig. 4 illustrates the current harmonic spectrum of the inductor under analysis. Results from Fig. 2 to Fig. 4 show that the unsuitable $S R F$ causes distortion in the inductor current given the harmonics in the capacitive region beyond of the $S R F$ of $22 \mathrm{MHz}$. 


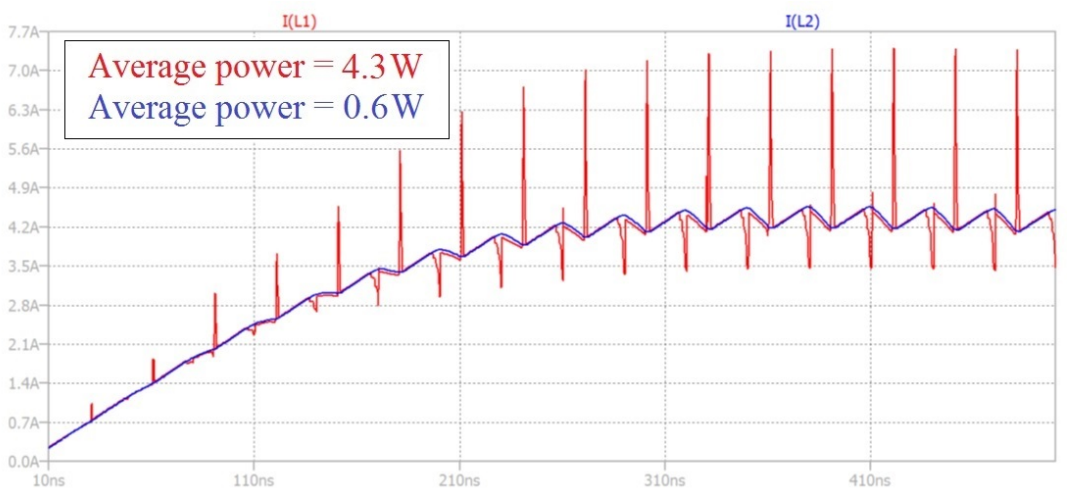

Figure 3: Inductor current. Color nomenclature: blue - ideal inductor in series with a low resistance, red - inductor under study.

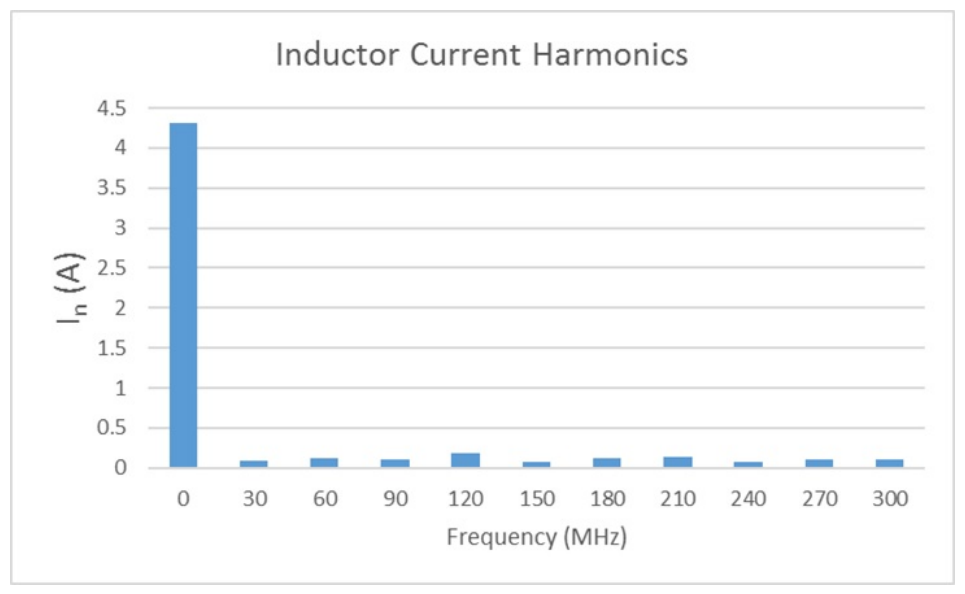

Figure 4: Current harmonic spectrum for the studied inductor.

In addition, the low $Q$ parameter causes important power losses in comparison with the ideal inductor in series with a low resistance. These power losses in the time-domain are associated to the interactions between the inductor harmonics and the inductor behavior in high-frequency. Next section will discuss these interactions using the Parseval's theorem, which describes the energy conservation in the frequency-domain and the time-domain. 


\section{Parseval's theorem approach}

As described in the previous study case, the wrong selection of the power inductor leads to low signal quality and higher losses in high-frequency power converters. As a result, the following theoretical approach provides insights about the relation between power and frequency of inductors suitable for high-frequency power converters.

Considering the approach described in [12] and defining the inductor current $i(t)$ and the inductor voltage $v(t)$, the electrical energy $U_{L}$ for an inductor in the time-domain is given by eq.(1).

$$
U_{L}=\int_{-\infty}^{\infty} p(t) d t=\int_{-\infty}^{\infty} i(t) v(t) d t
$$

In the frequency-domain, the convolution theorem applied to the power expression $i(t) v(t)$ of eq.(1) is given by eq.(2),

$$
\mathscr{F}\{i(t) v(t)\}=I(f) * V(f)
$$

where $I(f), V(f)$ are the complex valued Fourier transforms. $\mathscr{F}$ denotes Fourier transform, and $*$ denotes convolution. By definitions of Fourier transform $\mathscr{F}$ and convolution, the eq.(2) becomes eq.(3),

$$
\int_{-\infty}^{\infty} i(t) v(t) e^{-j 2 \pi \sigma} d t=\int_{-\infty}^{\infty} I(f) V(\sigma-f) d f
$$

the evaluation of the Fourier transform at the origin $(\sigma=0)$ equals the integrals over all their domains [REF REF]. Thus, the electrical energy $U_{L}$ from eq.(1) can be expressed by eq.(4), where $\overline{V(f)}$ is the complex conjugated of $V(f)$, 


$$
\int_{-\infty}^{\infty} i(t) v(t) d t=\int_{-\infty}^{\infty} I(f) \overline{V(f)} d f
$$

therefore,

$$
\int_{-\infty}^{\infty} i(t) v(t) d t=\int_{-\infty}^{\infty} I(f) \overline{[I(f) Z(f)]} d f=\int_{-\infty}^{\infty} I(f)^{2} \overline{Z(f)} d f
$$

given that $Z(f)=R_{f}+j X_{L}$ is the complex impedance of the inductor and $X_{L}$ is an odd function [12],

$$
\int_{-\infty}^{\infty} i(t) v(t) d t=\int_{-\infty}^{\infty}|I(f)|^{2}\left(R_{f}-j X_{L}\right) d f=\int_{-\infty}^{\infty}|I(f)|^{2} R_{f} d f
$$

the result in eq.(6) illustrates the energy conservation between the time and the frequency domains. Therefore, eq.(6) can be seen as an extension of the Parseval's theorem [12]. The physical interpretation of eq.(6) is that the total energy $U_{L}$ of the inductor can be calculated by integrating power over time or by the spectral power across frequency known the current and the associated losses. The Parseval's identity define the relation between the average power of a signal $h(t)$ and their Fourier coefficients as,

$$
\frac{1}{T} \int_{-T / 2}^{T / 2}|h(t)|^{2} d t=\sum_{n=-\infty}^{\infty}\left|C_{n}\right|^{2}
$$

therefore, the average inductor power can be expressed from eq.(6) by,

$$
P_{A V G}=\frac{1}{T} \int_{0}^{T} i(t) v(t) d t=\sum_{n=0}^{N} I_{n}^{2} R_{f}
$$




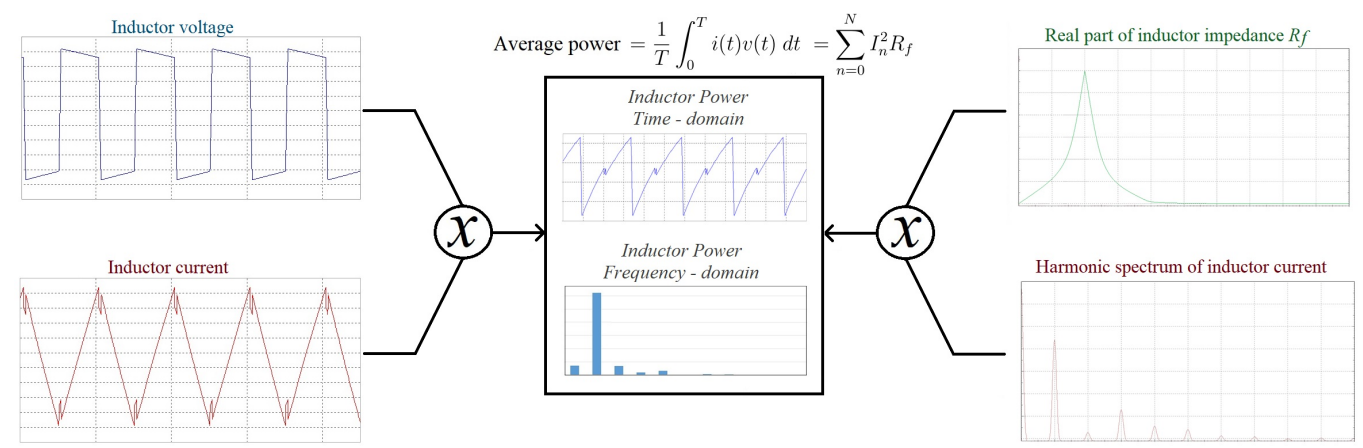

Figure 5: Extension of Parseval's theorem for the inductor analysis in power converters.

As a result, the average inductor power depends on the current harmonics $I_{n}$ and the associated inductor losses $R_{f}$ from the real part of the inductor impedance in the frequency-domain. Fig. 5 depicts an illustrative interpretation of the developed concept about the equivalence between the power in the time and the frequency domains. The right side criterion of eq.(8) is applied to the designed boost converter by means of the associated inductor losses $R_{f}$ and the current harmonics (see Fig. 2 and Fig. 4). The results for the average power in the time and frequency domains are summarizes in Fig. 6 and Fig. 7. These results agree with the expected energy conservation criterion.

Fig. 7 depicts the distribution of power losses in the frequency domain. Results in Fig. 7 show that harmonics higher than eight times the switching frequency $F_{s w}$ have a negligible impact on the power losses. In addition, this figure allows highlighting the contribution to the power losses of the current at the switching frequency. In this case, the higher losses are given at the switching frequency $F_{s w}$ despite of the very high ratio between the DC current and the current at $F_{s w}$. The relative high value of $R_{f}$ explains this power losses at the switching frequency $F_{s w}$. Therefore, it is fundamental to increase the quality factor $Q$ to decrease the $R_{f}$ losses at the switching frequency $F_{s w}$ in order to improve the global inductor efficiency.

Fig. 8 shows the relation of the power losses in the time domain against the quality factor at the switching frequency $Q\left(F_{s w}\right)$, 


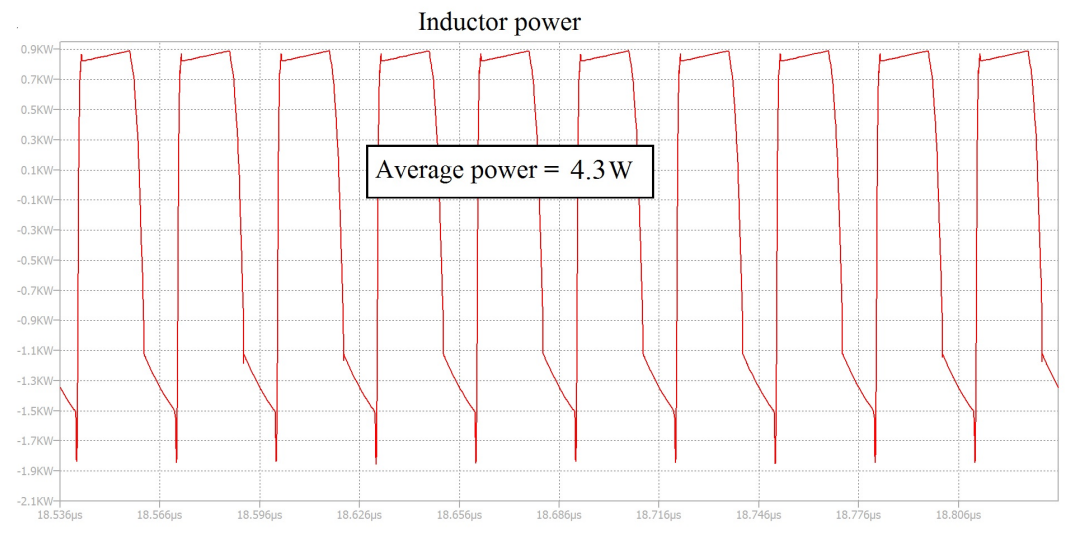

Figure 6: Inductor power in the time-domain.

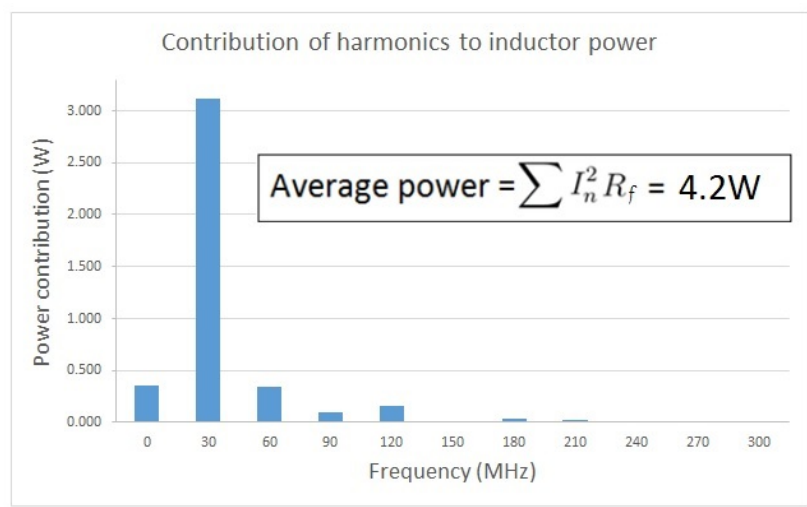

Figure 7: Inductor power in the frequency-domain.

$$
Q\left(F_{s w}\right)=\frac{X_{L}\left(F_{s w}\right)}{R_{f}\left(F_{s w}\right)}
$$

177

178

179

180

The plot is calculated from eq.(8) by assuming that the highest contribution to the power losses comes from the fundamental frequency at the switching frequency. To plot this figure, the $S R F$ is assumed to be eight times the switching frequency $F_{s w}$ and the $Q$ factor is evaluated at $30 \mathrm{MHz}$ for a fixed current spectrum. Results in Fig. 8 allow concluding that increasing considerably the $Q$ factor has low impact in the power losses since the 
reduction in power losses becomes negligible. Therefore, it is necessary an approach to the suitable selection of the $Q$ factor. In this context, the next section will propose a circuital model to include the $S R F$ and $Q$ parameters in the converter design process to assess their impact in the converter performance and to further inductor selection or manufacturing.

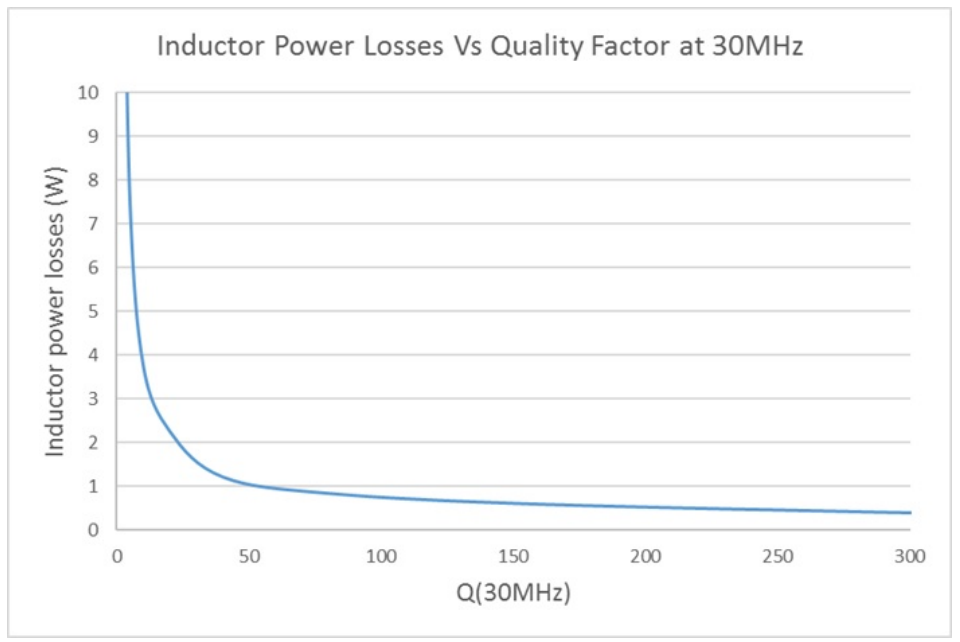

Figure 8: Inductor losses and quality factor $Q_{s w}$ at the switching frequency $F_{s w}$.

\section{Proposed inductor model including SRF and Q}

Currently, development of power electronics requires power inductors able to operate in high-frequency with high current capabilities. Therefore, the manufacturing specifications of $S R F$ and $Q$ should be useful to both power converter designers and inductor manufactures. As a result, this section provides a framework to integrate these parameters in the design process of power converters.

Fig. 9 describes a circuital model for actual inductors usually used for the circuit simulation tools. This model includes an ideal inductor $L$, a series resistance $R_{s}$, a parasite capacitance $C_{p}$, and a parallel losses resistance $R_{p}$.

For the inductor model of Fig. 9, the inductor impedance $Z$ is given by the eq.(10) at the switching frequency $F_{s w}$ and $\omega_{s w}=2 \pi F_{s w}$, 


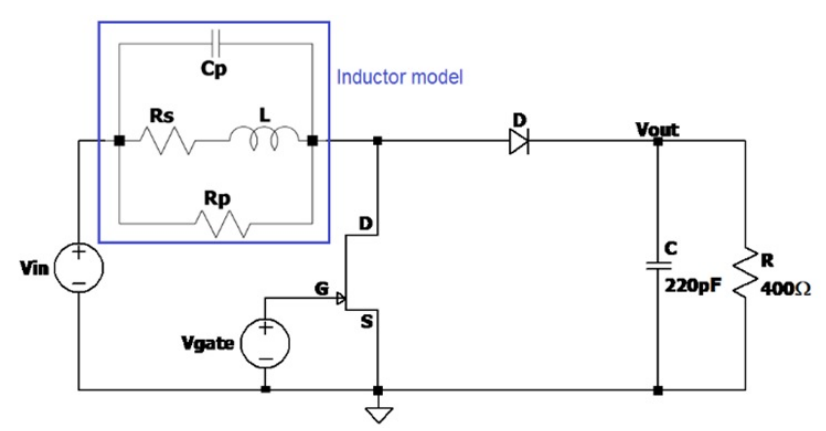

Figure 9: Boost converter with inductor model.

216

217

218

219

220

$$
Z=\frac{1}{\frac{1}{R_{p}}+\frac{1-\omega_{s w}^{2} L C_{p}+j \omega_{s w} C_{p} R_{s}}{R_{s}+j \omega_{s w} L}}
$$

considering the real and imaginary parts of $Z$ and solving for $Q_{s w}$, where $Q_{s w}$ is defined as the quality factor at the switching frequency $Q\left(F_{s w}\right)$, we have,

$$
Q_{s w}=\frac{\operatorname{Im}(Z)}{R e(Z)}=\frac{-R_{p}\left(\omega_{s w} C_{p} R_{s}^{2}-\omega_{s w} L+\omega_{s w}^{3} C_{p} L^{2}\right)}{R_{s}^{2}+\omega_{s w}^{2} L^{2}+R_{p} R_{s}}
$$

solving for $R_{p}$

$$
R_{p}=\frac{Q_{s w}\left(R_{s}^{2}+\omega_{s w}^{2} L^{2}\right)}{-\omega_{s w}^{3} C_{p} L^{2}+\omega_{s w} L-\omega_{s w} C_{p} R_{s}^{2}-Q_{s w} R_{s}}
$$

Additionally, the $S F R$ is defined by the inductor resonance frequency. Thus, the $C_{p}$ capacitance is given by,

$$
C_{p}=\frac{1}{(2 \pi)^{2}(S R F)^{2} L}
$$


Eq.(12) and eq.(13) allow including in the circuital inductor model the high-frequency parameters of Self Resonance Frequency $(S R F)$ and the quality factor at the switching frequency $Q_{s w}$. Therefore, these expressions are useful to simulate and evaluate the impact of the $S R F$ and $Q$ parameters on the power converter performance.

As illustrative example, the boost converter of Fig. 9 is simulated for $F_{s w}=30 \mathrm{MHz}, L=8.2 \mu \mathrm{H}$, and $R_{s}=0.2 \Omega . R_{p}$ and $C_{p}$ are calculated from eq. (12) and eq.(13). $Q_{s w}=100$ in the analyzed cases. The simulation results of Fig. 10 show the impact on the drain current of the GaN-HEMT transistor when $S R F$ is evaluated for $30 \mathrm{MHz}$ and $250 \mathrm{MHz}$. These results depicts the increasing in the drain current by around $50 \%$ which lead to an increase in the switching losses by around $20 \%$. This phenomenon is mainly generated by the increase of the parasitic capacitance $C_{p}$ when the $S R F$ parameter is lower.

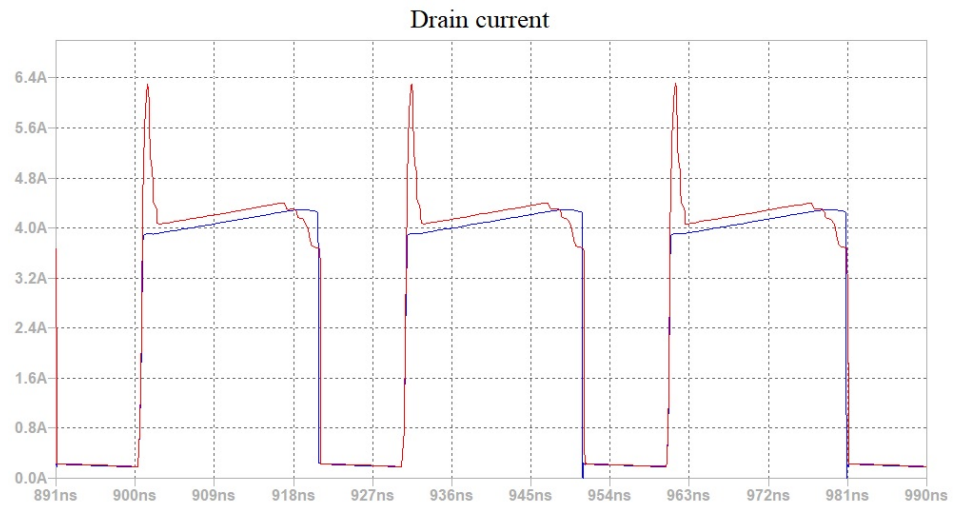

Figure 10: Impact of the $S R F$ on the drain current. Color nomenclature: blue - drain current for $S R F=250 \mathrm{MHz}$, red - drain current for $S R F=30 \mathrm{MHz}$.

Fig. 11 depicts the frequency behavior of the associated inductor losses $R_{f}$ and the quality factor $Q_{f}$ for a power inductor of $8.2 \mu \mathrm{H}, Q(30 \mathrm{MHz})=100$ and $S R F=250 \mathrm{MHz}$. Fig. 12 shows the inductor current for the aforementioned specifications in comparison with an ideal inductor. The frequency distribution of power losses are plotted in Fig. 13. This figure shows that 


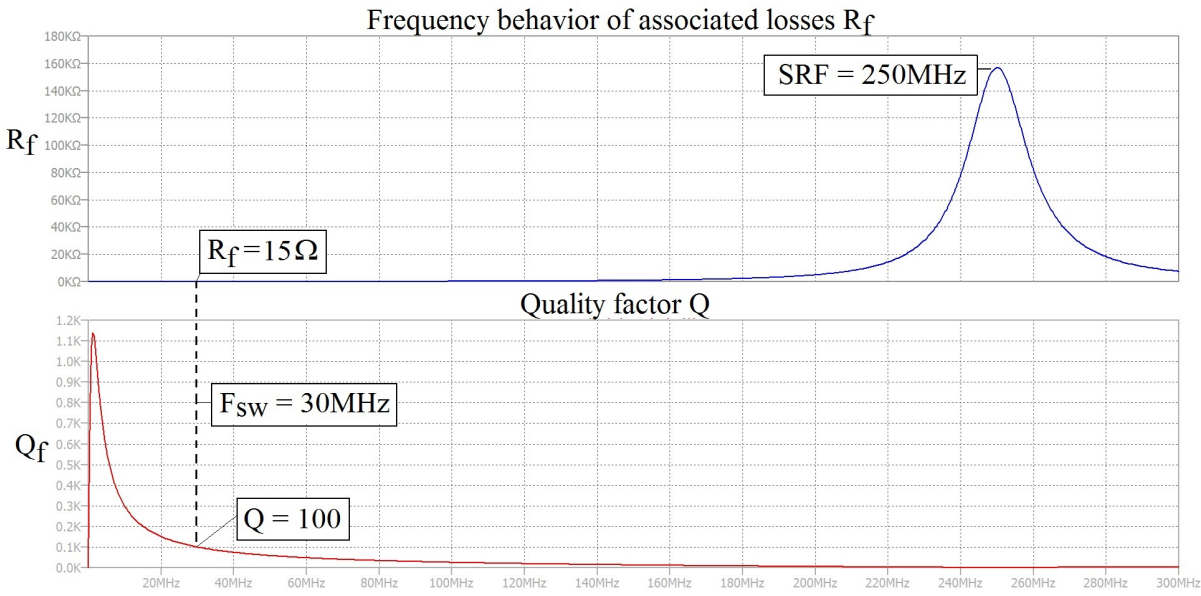

Figure 11: Frequency behavior of $R_{f}$ and $Q_{f}$ for the modeled inductor.

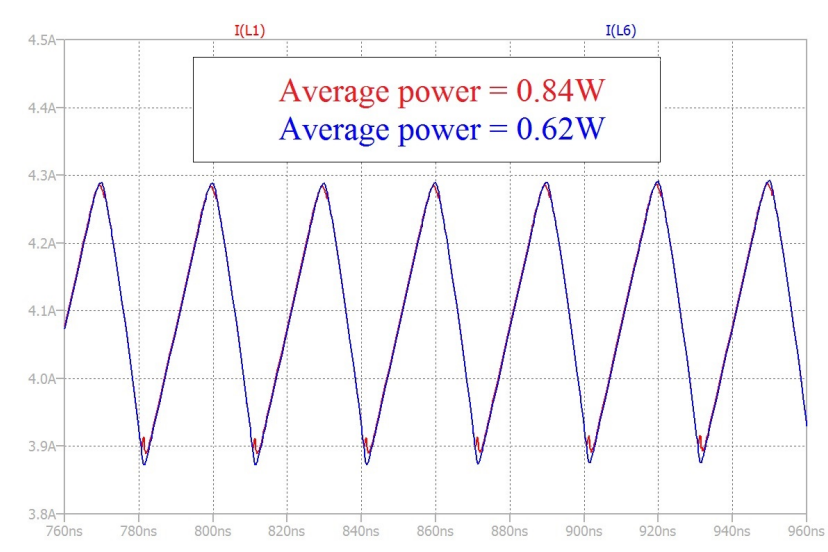

Figure 12: Inductor current. Color nomenclature: blue - ideal inductor with low series resistance, red - power inductor considering $Q(30 \mathrm{MHz})=100$ and $S R F=250 \mathrm{MHz}$.

the selected inductor drastically decreases the power losses at the switching frequency.

The proposed analysis for power inductors has been described through this document. The simulated results have shown a suitable trade-off between power and frequency performance. Next section will introduce the experimental setup to validate the proposed approach. 


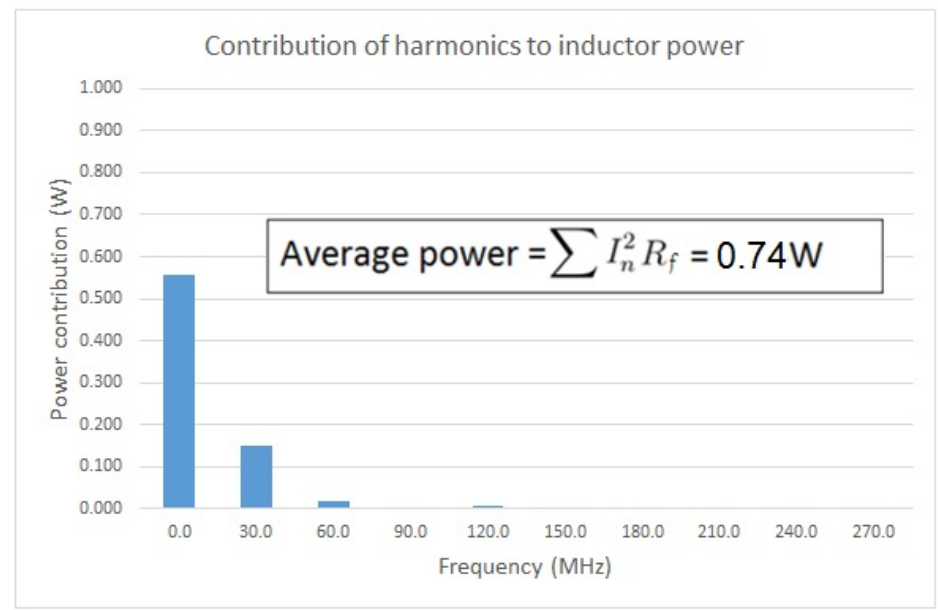

Figure 13: Inductor power distribution in the frequency-domain for $Q(30 \mathrm{MHz})=100$ and $S R F=250 \mathrm{MHz}$.

\section{Experimental results}

This section describes the performed tests. First, the power inductors are measured and the circuital models are validated. Then, an experimental setup allows verifying the described power equivalence between the time and frequency domains. Finally, an experimental boost converter provides results about the performance of a conventional power inductor in a relative highfrequency.

\subsection{Inductor circuital model and characterization}

This test employs an impedance analyzer Agilent 4294A to measure the parameters of several power inductors. The impedance analyzer sweeps the frequency from $40 \mathrm{~Hz}$ to $110 \mathrm{MHz}$ and it measures $Z-\theta, R-X$ and $L-Q$. Table 1 summarizes the measured and calculated parameters. $R_{p}$ and $C_{p}$ calculated from eq.(12) to eq.(13) selecting the $Q$ factor at $10 \mathrm{MHz}$ in all cases. Fig. 14 depicts the simulated and measured $R_{f}$ (the real part of the inductor impedance) for the inductor SRP5015TA. The MAPE (Mean Absolute Percentage Error) evaluates the model accuracy using eq.(14) where $M_{K}$ is the measured value and $S_{k}$ is the simulated value. As listed in Table 1 , the MAPE shows a partial agreement between the experimental data and the circuital model. 
272

277

$$
M A P E=\frac{1}{n} \sum_{k=1}^{n}\left|\frac{M_{k}-S_{k}}{M_{k}}\right|
$$

However, Fig. 14 allows concluding that values for frequencies farther to the selected $Q$ at $10 \mathrm{MHz}$ have less agreement than values around the selected $Q$. Therefore, the circuital model can slightly lose accuracy in a wide range of frequencies.

Table 1: Characterization and modeling of inductors

\begin{tabular}{cccccccc}
\hline & \multicolumn{3}{c}{ Measure } & \multicolumn{4}{c}{ Calculation } \\
\hline Inductor Ref. & $\begin{array}{c}\mathrm{L} \\
(\mu \mathrm{H})\end{array}$ & $\begin{array}{c}\mathrm{Rs} \\
(\mathrm{m} \Omega)\end{array}$ & $\begin{array}{c}\mathrm{Q} \\
(10 \mathrm{MHz})\end{array}$ & $\begin{array}{c}\mathrm{SRF} \\
(\mathrm{MHz})\end{array}$ & $\begin{array}{c}\mathrm{Rp} \\
(\mathrm{K} \Omega)\end{array}$ & $\begin{array}{c}\mathrm{Cp} \\
(\mathrm{pF})\end{array}$ & MAPE \\
\hline SRP5015TA-8R2M & 7.8 & 190 & 25.5 & 24.2 & 15.3 & 5.6 & 0.28 \\
SRR1210-8R2Y & 7.3 & 4.1 & 15.4 & 21.1 & 9.1 & 7.9 & 0.27 \\
7447713082 & 7.7 & 29 & 13.2 & 29.8 & 7.2 & 3.7 & 0.28 \\
744314850 & 8.2 & 24 & 7.7 & 35.4 & 4.3 & 2.5 & 0.15 \\
\hline
\end{tabular}

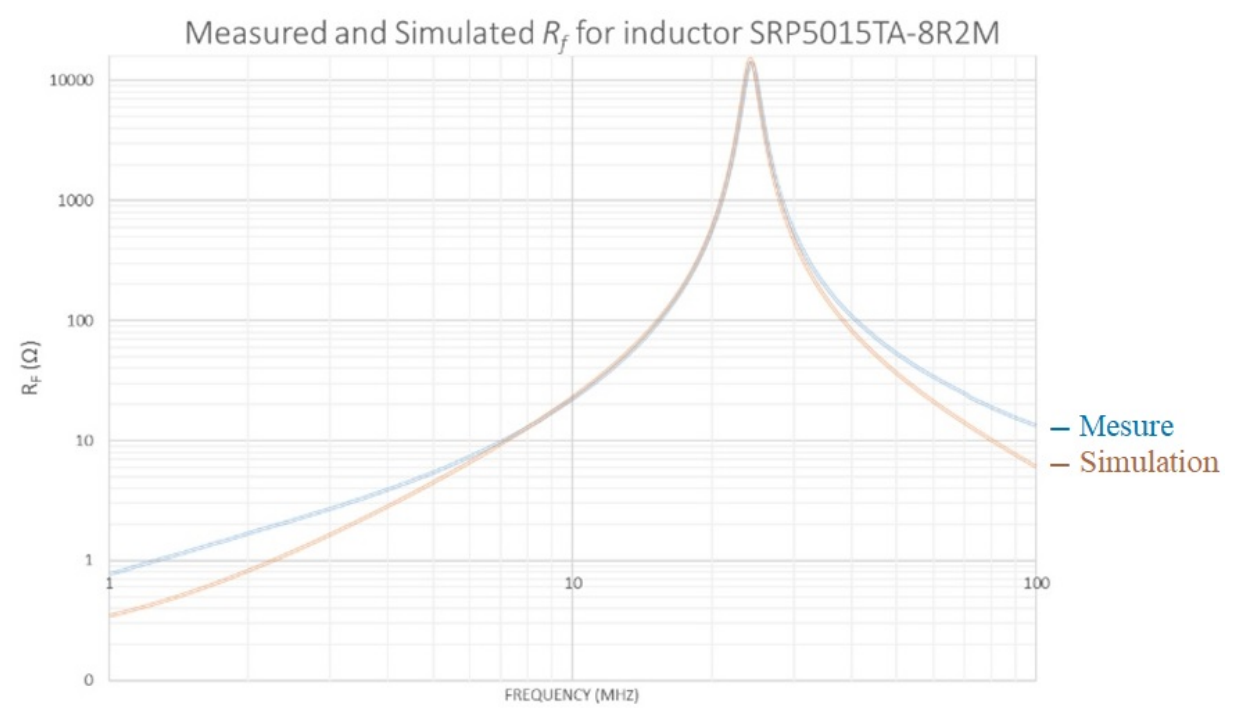

Figure 14: Real part of inductor impedance $\left(R_{f}\right)$. Inductor reference SRP5015TA-8R2M. 


\subsection{Inductor power in the time-domain and the frequency-domain}

In this experimental setup, a waveform generator (33612A Keysight) provides a square signal of $5 \mathrm{Vpp}$ to the inductor under test. The current probe (Tektronix CT2) measures the inductor current, and the active probe(RTZS20 R\&S) measures the voltage. The oscilloscope (RTO-1044 R\&S) records the waveforms and calculates the average power in the time domain and the inductor current FFT (Fast Fourier Transform) in the frequency domain. The test is carried out at $10 \mathrm{MHz}$ and $30 \mathrm{MHz}$. The aim of this test is to validate the power equivalence using the proposed approach.

Fig. 15 depicts the waveforms for square signals of case (a) for $10 \mathrm{MHz}$ and case (b) for $30 \mathrm{MHz}$ for the power inductor SRP5015A. In the case (a), the fundamental frequency is lower than the $S R F$. Therefore, the inductor is able to store energy as a magnetic field with relative low power loss. In contrast, the case (b) has a fundamental frequency higher than the $S R F$. As result, the inductor behaves as a capacitor distorting the current signal and increasing the power loss.

Fig. 16 shows the FFT for the inductor current of case (a) in Fig. 15a. In Table 2, the contribution of each harmonic is calculated from the measured $R_{f}$ (see Fig. 14) and the FFT (see Fig. 16) for the fundamental and harmonic frequencies using expression eq.(15). Results from Fig. 15a and Table 2 agree with the expected correlation between the power in the time and frequency domains.

$$
P_{A V G}=\frac{1}{T} \int_{0}^{T} i(t) v(t) d t=\sum_{n=0}^{N} I_{n}^{2} R_{f}
$$

Table 2: Inductor power frequency-domain (SRP5015A). Test at $10 \mathrm{MHz}$ - square signal.

\begin{tabular}{cccccccc}
\hline Freq. $(\mathrm{MHz})$ & 0 & 10 & 30 & 50 & 70 & 90 & Total \\
\hline $\mathrm{P}_{h}(\mu \mathrm{W})$ & 0.03 & 197 & 14 & 4.8 & 2.9 & 1.7 & 220 \\
\hline
\end{tabular}




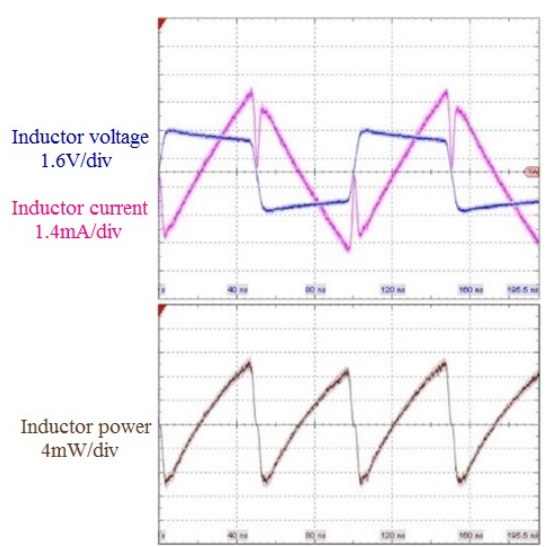

(a) Test at $10 \mathrm{MHz} . \mathrm{P}_{\text {avg }}=239 \mu \mathrm{W}$. Time-scale: $40 \mathrm{~ns} / \mathrm{div}$

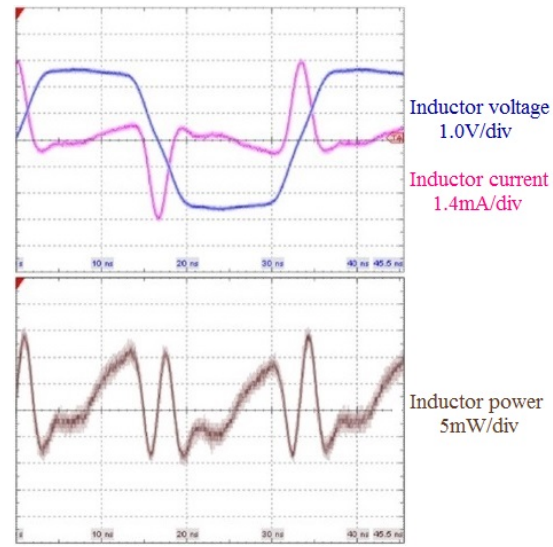

(b) Test at $30 \mathrm{MHz} . \mathrm{P}_{\text {avg }}=848 \mu \mathrm{W}$. Time-scale: $10 \mathrm{~ns} / \mathrm{div}$

Figure 15: Test inductor SRP5015A at 10MHz and 30MHz.

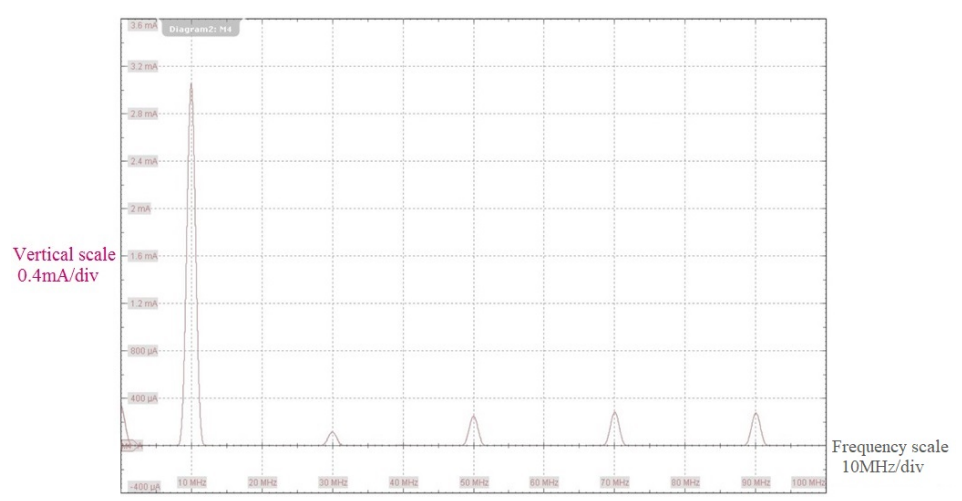

Figure 16: FFT of inductor current for test at $10 \mathrm{MHz}$ - square signal. Inductor reference SRP5015A.

Table 3 summaries the power results for the measured inductors. These results confirm the duality between the inductor power in the time-domain and the frequency-domain. However, differences between theoretical and experimental results are mainly caused by the shifting of the $S R F$ given the parasitic capacitance and inductance of the current and voltage probes.

\subsection{Boost converter at $1 \mathrm{MHz}$}

This test implements a boost converter at $1 \mathrm{MHz}$. The boost converter specification are $V_{\text {in }}=30 \mathrm{~V}, V_{\text {out }}=60 \mathrm{~V}, P_{\text {out }}=40 \mathrm{~W}$, and inductor current $I_{L}=1.5 \mathrm{~A}$ 
Table 3: Inductor power in the time and frequency

\begin{tabular}{ccccc}
\hline & \multicolumn{2}{c}{ SRP5015TA-8R2M } & \multicolumn{2}{c}{ SRR1210-8R2Y } \\
& $10 \mathrm{MHz}$ & $30 \mathrm{MHz}$ & $10 \mathrm{MHz}$ & $30 \mathrm{MHz}$ \\
\hline Power time $(\mu \mathrm{W})$ & 239 & 848 & 257 & 925 \\
Power freq. $(\mu \mathrm{W})$ & 220 & 760 & 235 & 857 \\
\hline \hline & \multicolumn{2}{c}{7447713082} & \multicolumn{2}{c}{744314850} \\
& $10 \mathrm{MHz}$ & $30 \mathrm{MHz}$ & $10 \mathrm{MHz}$ & $30 \mathrm{MHz}$ \\
\hline Power time $(\mu \mathrm{W})$ & 285 & 1380 & 299 & 818 \\
Power freq. $(\mu \mathrm{W})$ & 262 & 1140 & 283 & 767 \\
\hline
\end{tabular}

considering an efficiency $\eta=0.9$. The design uses and inductor SRR1210-8R2 given its favorable quality factor $Q(1 \mathrm{MHz})=30$ and $S R F=22 \mathrm{MHz}$. The selected inductor SRR1210-8R2 has a series resistance $R_{s}=17 \mathrm{~m} \Omega$ and a saturation current of $7.5 \mathrm{~A}$. The switching frequency is set to $1 \mathrm{MHz}$ to ensure the eight harmonic lower than the $S R F$. A GaN-HEMT is used as a switching device. The achieved results harmonize with the theoretical framework. However, the slight deviation between the temporal and frequency responses can be overcame by improving the experimental setup decreasing the parasitic elements.

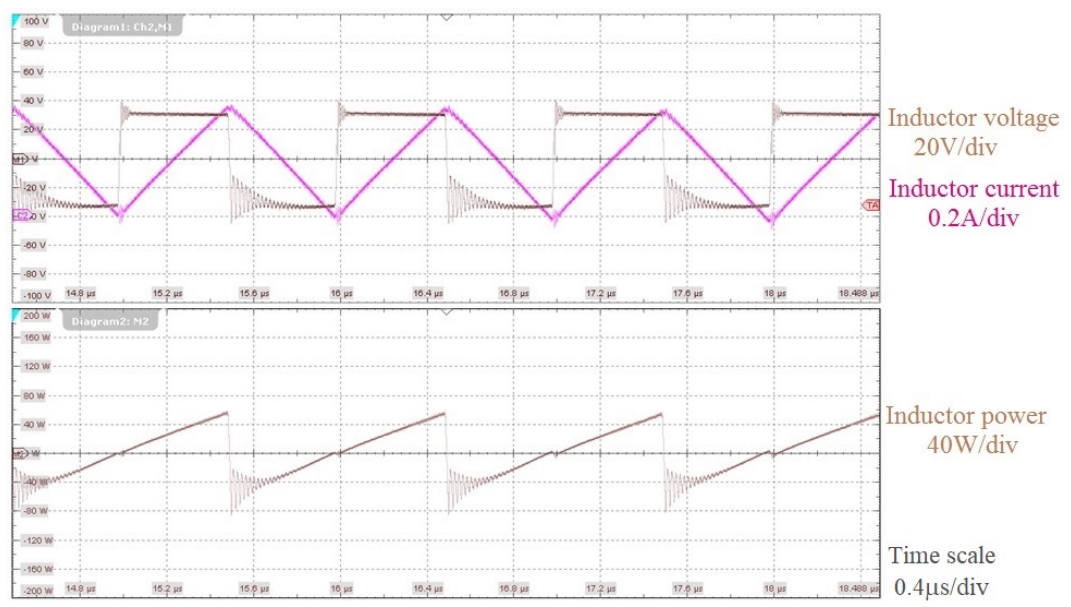

Figure 17: Experimental results for $1 \mathrm{MHz}$ boost converter. Inductor SRR1210-8R2. $\mathrm{P}_{\text {avg }}=492 \mathrm{~mW}$. 
Fig. 17 shows the inductor waveforms. The inductor average power in the time-domain is $\mathrm{P}_{\text {avg }}=492 \mathrm{~mW}$. Fig. 18 depicts the harmonic spectrum for the inductor current. Table 4 lists the power contribution of each harmonic to the total power. The total power in the frequency-domain is $\mathrm{P}_{a v g}=447 \mathrm{~mW}$. Results from Fig. 17 and Table 4 validate the equivalence between the power in the time and frequency domains. In additions, the results allow identifying that the behavior at the fundamental frequency is the main cause of the inductor power loss.

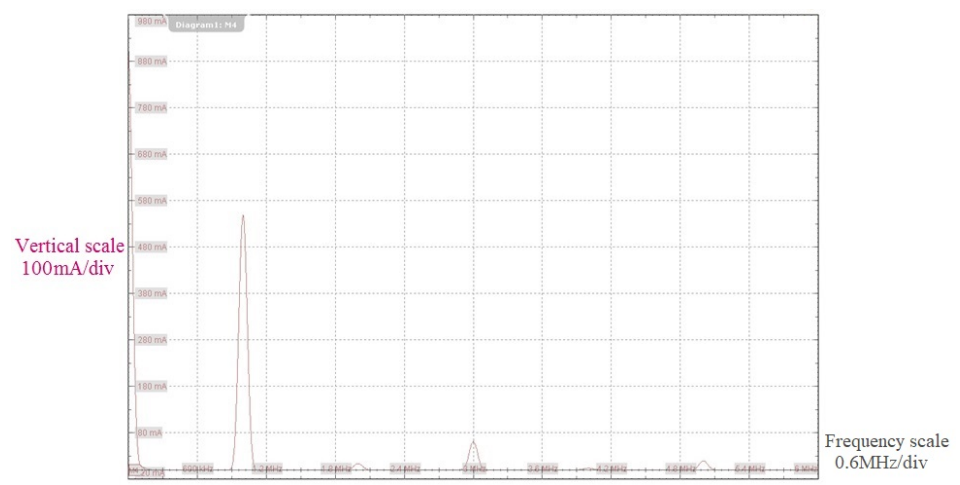

Figure 18: FFT for the inductor current of $1 \mathrm{MHz}$ boost converter.

Table 4: Inductor power in the frequency domain

\begin{tabular}{cccccccc}
\hline Freq.(MHz) & 0 & 1 & 2 & 3 & 4 & 5 & Total \\
\hline $\mathrm{P}_{h}(\mathrm{~mW})$ & 14 & 418 & 0.4 & 11 & 0.05 & 2.7 & 447 \\
\hline
\end{tabular}

\subsection{Boost converter for $400 \mathrm{~V}-400 \mathrm{~W}$ at $30 \mathrm{MHz}$}

This section shows the results of implementing a high-frequency boost converter. A power inductor was designed for this experimental setup. The designed inductor has specifications of $\mathrm{L}=8 \mu \mathrm{H}, \mathrm{I}_{\text {sat }}=3.5 \mathrm{~A}, Q(30 \mathrm{MHz})=25$ and $S R F=200 \mathrm{MHz}$. The switching device is a GaN-HEMT.

The boost converter is tested first at $V_{\text {out }}=60 \mathrm{~V}-\mathrm{P}_{\text {out }}=10 \mathrm{~W}$ and after at $V_{\text {out }}=400 \mathrm{~V}-\mathrm{P}_{\text {out }}=400 \mathrm{~W}$. The test is carried out first in relative low power to use available current probe (Tektronix CT2) because current probes for 


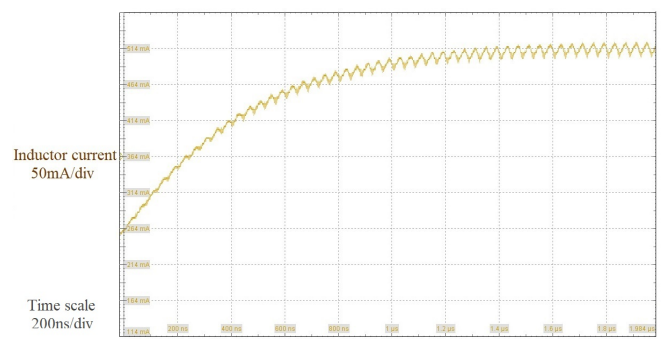

(a) Inductor current test at $60 \mathrm{~V}-30 \mathrm{MHz}$

high-current, high-voltage and high-frequency are currently under development. This represents a research challenge. In the second case, the inductor current is not measure for previous reasons. However, the global power converter results shows the suitable performance of the designed inductor.

In the first test, the specifications of the boost converter are $V_{i n}=30 \mathrm{~V}$, $V_{\text {out }}=60 \mathrm{~V}$, and $\mathrm{P}_{\text {out }}=10 \mathrm{~W}$ at $30 \mathrm{MHz}$. Fig. 19 shows the waveforms for the power inductor. In this case, the average power was $\mathrm{P}_{\text {avg }}=780 \mathrm{~mW}$ in the time-domain and $\mathrm{P}_{a v g}=700 \mathrm{~mW}$ in the frequency-domain.

Figure 19: Inductor current and voltage for boost converter $60 \mathrm{~V}-10 \mathrm{~W}$ at $30 \mathrm{MHz}$
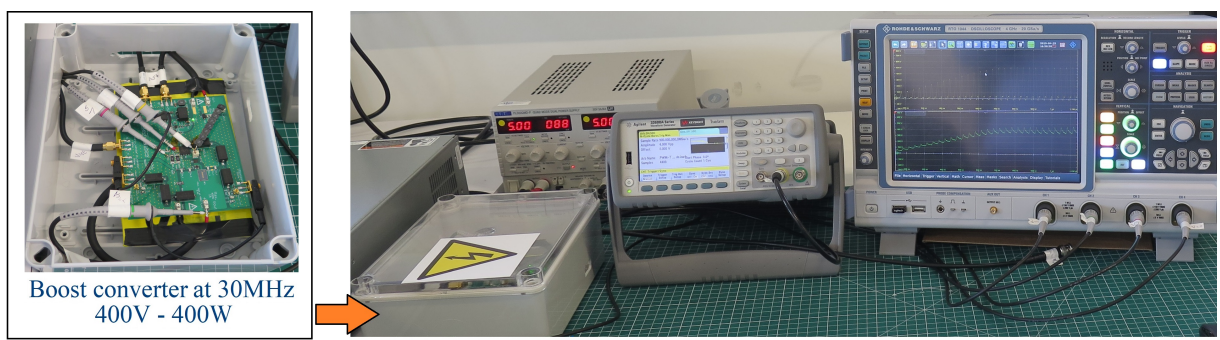

Figure 20: Experimental setup boost converter 400V - 400W at 30MHz.

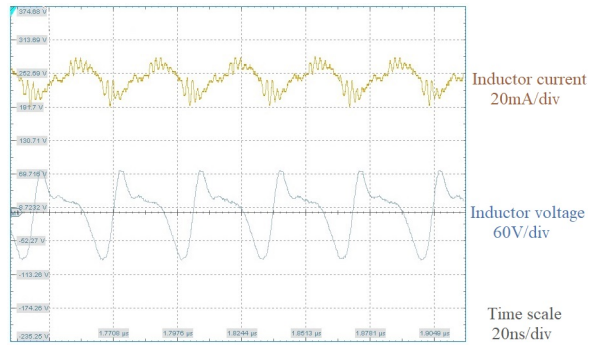

(b) Inductor current and voltage

For the second test, the implemented high-frequency boost converter has specifications of $V_{\text {in }}=200 \mathrm{~V}, V_{\text {out }}=400 \mathrm{~V}, \mathrm{P}_{\text {out }}=400 \mathrm{~W}$ at $30 \mathrm{MHz}$. Fig. 20 shows the experimental setup for the high-frequency boost converter. Additionally, result of Fig. 21 depicts the behavior of the output voltage. As shown in Fig. 21 , the designed boost converter is able to increase the input voltage from $200 \mathrm{~V}$ to $400 \mathrm{~V}$ with an output load of $400 \mathrm{~W}$. The switching frequency is set to $30 \mathrm{MHz}$ to assess the GaN-HEMT devices at high-voltage and high-frequency given a suitable performance. As a consequence, these results confirm the 
pertinence of the developed modeling approach to analyze and design power inductors to take advantages of the switching characteristics of GaN-HEMT devices.

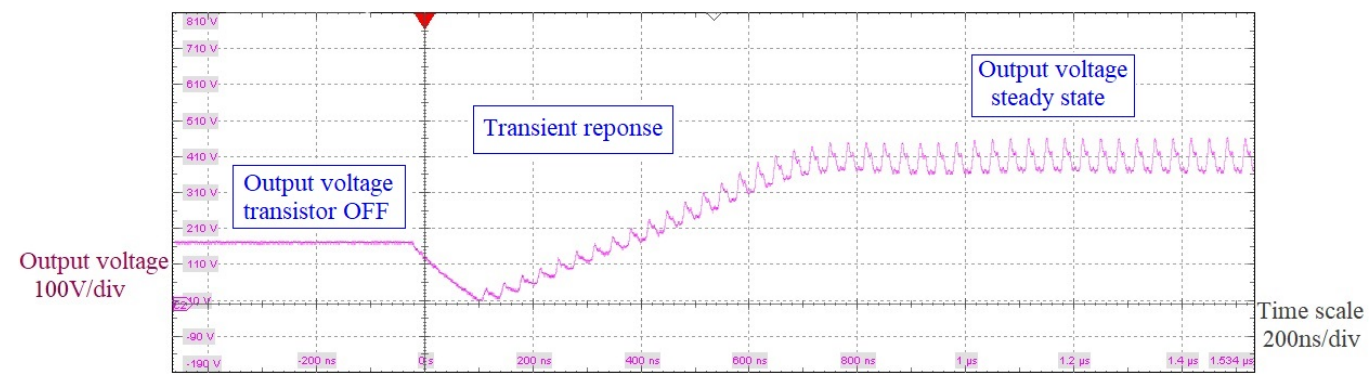

Figure 21: Output voltage of boost converter $400 \mathrm{~V}-400 \mathrm{~W}$ at $30 \mathrm{MHz}$.

\section{Conclusions}

The reported methodology has associated the analysis in the time and frequency domains for inductors in power converters using an extension of the Parseval's theorem. The proposed approach is complementary to conventional methodologies for the design of power converters. This analysis methodology allowed determining suitable criteria for the selection and simulation of inductors according to expected power losses. The proposed approach allowed disaggregating the power losses in the frequency-domain for complex inductor power signals in the time-domain. The study of the quality factor $Q$ allowed concluding that increasing considerably $Q$ has low impact on the power losses since the reduction in power losses becomes negligible. Therefore, a moderate $Q$ factor can be selected to achieve a trade-off between inductor performance and manufacturing feasibility. Additionally, the Self Resonance Frequency $S R F$ around eight times the switching frequency is a suitable criterion to avoid inductor current distortion. The proposed model in this work included frequency parameters of inductors in the design process of power converters. The experimental results have validated the proposed approach. However, the experimental setup should decrease the parasitic inductance and capacitance to minimize the measurement disturbances at high-frequency. 


\section{Acknowledgments}

This work has been partially funded by the Region Occitanie PyreneesMediterranee.

\section{References}

[1] P. Ning, T. Yuan, Y. Kang, C. Han, and L. Li, "Review of si igbt and sic mosfet based on hybrid switch," Chinese Journal of Electrical Engineering, vol. 5, pp. 20-29, Sep. 2019.

[2] J. Kashiwagi, A. Yamaguchi, Y. Moriyama, and K. Nakahara, "Hysteretic control embedded boost converter operating at 25-mhz switching," IEEE Transactions on Circuits and Systems II: Express Briefs, vol. 66, pp. 101-105, Jan 2019.

[3] A. Hariya, K. Matsuura, H. Yanagi, S. Tomioka, Y. Ishizuka, and T. Ninomiya, "Five-megahertz pwm-controlled current-mode resonant dc-dc step-down converter using gan-hemts," IEEE Transactions on Industry Applications, vol. 51, pp. 3263-3272, July 2015.

[4] M. Rodríguez, Y. Zhang, and D. Maksimovic, "High-frequency pwm buck converters using gan-on-sic hemts," IEEE Transactions on Power Electronics, vol. 29, pp. 2462-2473, May 2014.

[5] A. Hilal and B. Cougo, "Optimal inductor design and material selection for high power density inverters used in aircraft applications," in 2016 International Conference on Electrical Systems for Aircraft, Railway, Ship Propulsion and Road Vehicles International Transportation Electrification Conference (ESARS-ITEC), pp. 1-6, Nov 2016.

[6] W. Liang, L. Raymond, and J. Rivas, "3-d-printed air-core inductors for high-frequency power converters," IEEE Transactions on Power Electronics, vol. 31, pp. 52-64, Jan 2016.

[7] A. F. Jaimes, F. L. Cabrera, and F. R. de Sousa, "Characterization of high- $q$ inductors up to its self-resonance frequency for wireless power transfer applications," IEEE Microwave and Wireless Components Letters, vol. 28, pp. 1071-1073, Dec 2018. 
[8] D. C. Corrêa, U. C. Resende, and F. S. Bicalho, "Experiments with a compact wireless power transfer system using strongly coupled magnetic resonance and metamaterials," IEEE Transactions on Magnetics, vol. 55, pp. 1-4, Aug 2019.

[9] Kaiwei Yao, Yang Qiu, Ming Xu, and F. C. Lee, "A novel windingcoupled buck converter for high-frequency, high-step-down dc-dc conversion," IEEE Transactions on Power Electronics, vol. 20, pp. 1017-1024, Sep. 2005.

[10] E. L. Barrios, A. Urtasun, A. Ursúa, L. Marroyo, and P. Sanchis, "Optimal dc gapped inductor design including high-frequency effects," in IECON 2015 - 41st Annual Conference of the IEEE Industrial Electronics Society, pp. 003928-003933, Nov 2015.

[11] R. Barrera-Cardenas, T. Isobe, and M. Molinas, "Optimal design of aircore inductor for medium/high power dc-dc converters," in 2016 IEEE 17th Workshop on Control and Modeling for Power Electronics (COMPEL), pp. 1-8, June 2016.

[12] S. S. Kelkar, L. L. Grigsby, and J. Langsner, "An extension of parseval's theorem and its use in calculating transient energy in the frequency domain," IEEE Transactions on Industrial Electronics, vol. IE-30, pp. 4245, Feb 1983. 